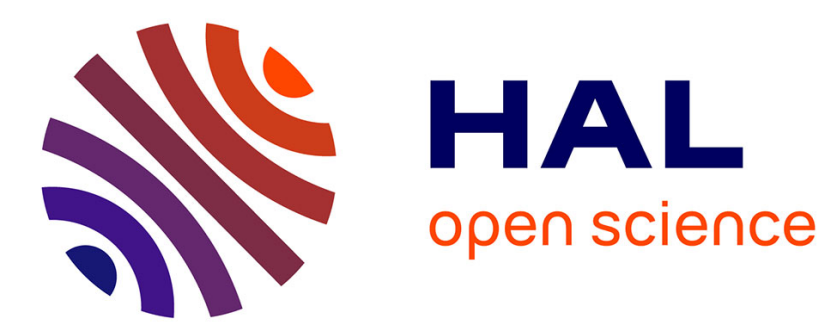

\title{
Structural interpretation of a new twin in staurolite from Coray, Brittany, France
}

\author{
Massimo Nespolo, Yves Moelo
}

\section{To cite this version:}

Massimo Nespolo, Yves Moelo. Structural interpretation of a new twin in staurolite from Coray, Brittany, France. European Journal of Mineralogy, 2019, 31 (4), pp.785-790. 10.1127/ejm/2019/00312849. hal-02308215

\section{HAL Id: hal-02308215 https://hal.univ-lorraine.fr/hal-02308215}

Submitted on 8 Oct 2019

HAL is a multi-disciplinary open access archive for the deposit and dissemination of scientific research documents, whether they are published or not. The documents may come from teaching and research institutions in France or abroad, or from public or private research centers.
L'archive ouverte pluridisciplinaire HAL, est destinée au dépôt et à la diffusion de documents scientifiques de niveau recherche, publiés ou non, émanant des établissements d'enseignement et de recherche français ou étrangers, des laboratoires publics ou privés. 


\title{
Structural interpretation of a new twin in staurolite from Coray, Brittany, France
}

\author{
Massimo NESPOLO ${ }^{1}$ and Yves MOËLO ${ }^{2}$ \\ ${ }^{1}$ Université de Lorraine, CNRS, CRM2, Nancy, France. \\ Corresponding author, email massimo.nespolo@univ-lorraine.fr \\ ORCID 0000-0003-2530-5399 \\ ${ }^{2}$ Institut des Matériaux Jean Rouxel, UMR 6502, CNRS, Université de Nantes, 2, 2 Rue \\ Houssiniere, F-44322 Nantes 3, France
}

9 Abstract: A new twin in staurolite has been recently reported from Coray (Brittany, France). From

morphological measurements the twin plane has been identified as (202), which corresponds to

11 twinning by reticular pseudomerohedry with index 3 and obliquity $0.97^{\circ}$. On the basis of the high-

12 degree of lattice restoration, significantly higher than that in the other well-known twins in

13 staurolite (Greek cross and Saint Andrews cross), one would expect a high probability of occurrence

14 for this twin. Its rarity can be explained on structural bases. The interface corresponding to the twin

15 plane corresponds to a highly disrupted coordination, where only half of the tetrahedra are restored.

16 This makes a contact twin highly unlikely. The reported twin is actually a penetration twin, in which

17 the irregular composition surface may have compensated, to some extent, the unfavourable

18 structural match.

19 Key-words: staurolite; crystallographic orbits; twinning.

\section{Introduction}

21 Staurolite is a well-known index mineral used to estimate the degree of metamorphism of the host

22 regional metamorphic rocks. The idealised formula of staurolite can be written as $\mathrm{X}_{9}$

$\left.23{ }_{12} \mathrm{Y}_{2} \mathrm{Z}_{4} \mathrm{O}_{20}(\mathrm{O}, \mathrm{H})\right)_{4}$, with ${ }^{[6]} \mathrm{X}=\left(\mathrm{Al}^{3+}, \mathrm{Fe}^{2+}, \square\right),{ }^{[4]} \mathrm{Y}=\left(\mathrm{Fe}^{2+}, \mathrm{Mg}^{2+}\right)$ and ${ }^{[4]} \mathrm{Z}^{2} \mathrm{Si}^{4+}(\square$ means vacancy $)$. The

24 structure is based on a slightly distorted $f c c$ packing of oxygen atoms, with the cations partly

25 occupying the octahedral $\left({ }^{[6]}\right)$ and tetrahedral $\left({ }^{[4]}\right)$ cavities. The distribution of the cations results in a 
space group of type $C 2 / m$, with however a lattice that is metrically orthorhombic or very close to orthorhombic. The cell parameters reported by Hawthorne et al. (1993), and used hereafter, are $a=$ $7.8695(3) \AA, b=16.6076(6) \AA, c=5.6658(2) \AA, \beta=90^{\circ}$.

Smith (1968) called staurolite "an enigma" because of the high frequency of occurrence of its two well-known twins, the $90^{\circ}$ twin or Greek cross twin, and the $60^{\circ}$ twin or Saint Andrews cross twin ${ }^{1}$. Hurst et al. (1956) showed that these are rotation twins, and not reflection twins as often reported in the literature. Nespolo \& Ferraris (2007), by applying the theory of hybrid twinning (Nespolo \& Ferraris, 2006), were able to remove the apparent contradiction related to a higher twin index in the more frequent Saint Andrews cross twin, showing that the two twins actually have the same twin index, once the Saint Andrews cross twin is treated as a hybrid twin. This did not however explain why the two twins have a different frequency of occurrence. The explanation was obtained by Marzouki et al. (2014b), by applying the structural analysis based on the study of the eigensymmetry of crystallographic orbits² (Marzouki et al., 2014a). The "staurolite enigma" was therefore considered solved, until Moëlo (2018) reopened it by reporting the first occurrence of a new twin from Coray (Finistère department, Brittany, France), which, as we are going to show, has

41 a lower twin index than the two other well-known twins.

42 The studied sample comes from the well-known staurolite-rich micaschist area close to Coray, a 43 little town in the South of Finistère department, Brittany, France (Chauris, 2014). The twin (Figs. 1 and 2) is a penetration twin in which the two individuals make an angle of about $108^{\circ}$ between the respective $c$ axes (Moëlo, 2018). The possible twin plane belongs therefore to the form $\{202\}$, which corresponds to an angle of $108.5^{\circ}$ between the $c$ axes of the two individuals (computed with $110-109^{\circ}$ ) between the respective $b$ axes. To the best of our knowledge, this twin has never been found later.

2 A crystallographic orbit is the infinite set of atoms obtained from one atom in the asymmetric unit by applying all the operations of the space group. 
47 the software Twiny: Nespolo \& Iordache, 2013) $)^{3}$. The direction quasi-perpendicular to the plane 48 (202) is [102], resulting in twin index 3 and obliquity $0.97^{\circ}$ (computed with the software

49 Geminography: Nespolo \& Ferraris, 2006); from the reticular viewpoint, this twin is therefore by 50 reticular pseudomerohedry (Friedel, 1904). For comparison, the Greek cross twin has index 6 and 51 obliquity $1.33^{\circ}$, whereas the Saint Andrews cross twin has effective twin index 6.0 and obliquities $521.01^{\circ}$ and $6.12^{\circ}$ respectively for the two concurrent sublattices. The rarity of the Coray twin is

53 therefore in striking contrast with the predictions of the reticular theory of twinning, according to

54 which the occurrence frequency should be inversely proportional to the twin index and obliquity.

55 The reticular theory of twinning provides, however, only the necessary conditions: whereas a twin

56 with very high twin index should not occur (when it does, it normally is a hybrid twin), a twin with

57 low index does not necessarily occur. This is precisely the situation in staurolite. To explain the 58 rarity of the Coray twin we need to analyse the structure at the interface.

\section{$59 \quad 2$ Structural analysis of the Coray twin in staurolite}

60 Twinning can occur as the result of a phase transition (transformation twins), of a physical action

61 (mechanical twins) or as a perturbation of the process of nucleation and crystal growth (growth twins). Transformation twins typically result in domain structures, in which several physically distinct domains are distributed over a few (often two) orientations (domain states) (Nespolo, 2015b). In mechanical twins, the interface between individuals are characteristically plane (Buerger, 1945), so that this type of twinning should result in contact twins. The Coray twin in staurolite being a penetration twin with two macroscopic individuals clearly visible, it must be a growth twin. A growth twin is the result of a change in orientation during crystal growth, or of the oriented

3 The (101) indexing in Moêlo (2018) has to be corrected to (202) because the conventional unit cell of staurolite is $C$-centred (Nespolo, 2015a).

4 The effective twin index is the generalization of the twin index to hybrid twins and is defined as the inverse of the fraction of the number of lattice nodes belonging to any of the concurrent sublattices based on the twin plane (or axis, for rotation twins) (Nespolo and Ferraris, 2005). 
68 attachment of crystals (Nespolo and Ferraris, 2004). Both origins can be seen as the result of a

69 perturbation with respect to normal crystal growth process, which results in a heterogeneous 70 crystalline edifice that should be less favourable, from a thermodynamic viewpoint (especially in its 71 enthalpic term), with respect to an untwinned crystal. When a twin occurs with a certain frequency,

72 there must be structural reasons that make the change in orientation a tolerable situation; otherwise,

73 the twin either does not form or occurs very occasionally. The two well-known cross twins of

74 staurolite correspond to the first situation, while the rare (so far unique) Coray twin must instead

75 belong to the second category. To ascertain whether this is really the case, we need to analyse the

76 pseudo-eigensymmetry of the crystallographic orbits to find whether it contains an operation whose

77 linear part coincides with the twin operation. The approach has been described in details in our

78 previous articles; in particular, we have shown that the cross twins of staurolite indeed present a good structural match across the interface, which justifies their occurrences (Marzouki et al. 2014b). The same approach allowed us to explain, from on a structural viewpoint, twinning in

81 melilite (Marzouki et al. 2014a), aragonite (Marzouki et al., 2015), marcasite (Nespolo and 82 Souvignier, 2015a), cassiterite/rutile (Nespolo \& Souvignier, 2015b), forsterite (Azevedo \&

83 Nespolo, 2017), chalcostibite (Nespolo, 2018) as well as the Carlsbad twin in orthoclase (Nespolo

$84 \&$ Souvignier, 2017). As we are going to show, the same approach explains the rarity of the Coray 85 twin.

86 The unit cell of the twin lattice of both the Greek cross twin and the Saint Andrews cross twin is based on the so-called Mallard's pseudo-cube ${ }^{5}$, i.e. a metrically cubic supercell whose basis vectors are obtained from those of staurolite by the transformation $\mathbf{b}+3 \mathbf{c},-\mathbf{b}+3 \mathbf{c}, 3 \mathbf{a}$. The structure of staurolite contains seven oxygen orbits; the union of all these orbits has pseudo-cubic $(f c c)$ symmetry and is therefore approximately restored by the twin operations. The individuals in both unit cell is $C$-centred and therefore not compatible with the cubic symmetry (Friedel, 1904). 
91 twins have therefore a substructure based on the oxygen atoms that is approximately common. The

92 higher occurrence frequency of the Saint Andrews twin was explained on the basis of a higher 93 degree of restoration for the cations (Marzouki et al., 2014b).

94 The unit cell of the twin lattice of the Coray twin is based on the [102]/(202) pair of lattice

95 elements. In the cubic basis of the Mallard's pseudo-cube these become [111]/(111). The [111] 96 direction (i.e. [102] in the setting of staurolite) corresponding to a threefold axis in a cubic 97 (sub)lattice: indeed, this direction acts as a three-fold rotation axis in the Greek cross twin. A 98 twofold rotation about the same axis is not a symmetry operation for a cubic (sub)lattice; neither is 99 a reflection through the (111) cubic plane. Therefore, the union of the oxygen orbits is no longer 100 restored in the Coray twin, as is instead the case in the cross twins. We have therefore to explicitly 101 obtain the degree of restoration for both the anions and the cations in this new twin.

102 The basis vectors of the individual ("I") and of the twin ("T") are related by the following 103 transformation:

$$
\left(\begin{array}{lll}
\mathbf{a} & \mathbf{b} & \mathbf{c}
\end{array}\right)_{\mathrm{I}}\left(\begin{array}{lll}
1 & 0 & \overline{1} \\
0 & 1 & 0 \\
2 & 0 & 1
\end{array}\right)=\left(\begin{array}{lll}
\mathbf{a} & \mathbf{b} & \mathbf{c}
\end{array}\right)_{\mathrm{T}}
$$

104 where [010] and [101] are the two shortest direction in the (202) plane at right angles from each 105 other. The cell parameters of the twin lattice are $a=13.796 \AA, b=16.608 \AA, c=9.697 \AA, \beta=$ $10689.03^{\circ}$ and the unit cell is $C$-centred (Fig. 3). The highest subgroup of $C 2 / m$ compatible with this 107 lattice is obtained as $\mathcal{H}=G_{1} \cap G_{2}$ where $G_{1}$ and $G_{2}$ are the space groups of the two individuals, both 108 of type $C 2 / m$, in the respective orientations; in particular $G_{2}$ is conjugate of $G_{1}$ with respect to the 109 twin operation. In our case, $G_{2}=m_{(202)} G_{1} m_{(202)}$ and $\mathcal{H}=C 2 / m$, i.e. an isomorphic subgroup of the 110 space group of the individual: same type of space group but whose translation subgroup is a 111 subgroup of the translation subgroup of the space group of the individual. In symbols, $\mathcal{T}(\mathcal{H}) \subset \mathcal{T}(G)$. 
112 The Miller indices of the twin plane in the axial setting of the twin are (200).

113 In order for a substructure of staurolite to cross the twin plane more or less unperturbed, the

114 crystallographic orbits building this substructure must contain, in their eigensymmetry, an

115 operation, known as the restoration operation, whose linear part coincides with the twin operation.

116 In the case of the Coray twin in staurolite, the twin operation is a mirror reflection through the (200)

117 plane (in the twin setting); the restoration operation can therefore be a mirror or glide reflection

118 through a plane parallel to (200). Fig. 4 shows a projection along the $b$ axis of the structure of

119 staurolite in the axial setting of the Coray twin, with planes of the (200) family on or close to

120 oxygen atoms - black planes at $(2 n+1) a / 12, n$ integer - on or close to the $\mathrm{X}$ atoms - grey planes at

$121 n a / 6, n$ integer. The two nearest planes of either set are $a / 6$ apart, while two nearest planes of 122 different sets are $a / 12$ apart. Twinning would be explained on a structural basis if any of these

123 planes is a pseudo mirror or glide plane for a significant subset of atoms close to that plane, because

124 in this case a significant substructure would cross the plane without a large deformation. Because of 125 the $C 2 / m$ symmetry, only two positions for the each of the two sets have to be considered, the others

126 being related by symmetry operations of the space group; in the following we analyse positions at $x$ $127=1 / 4$ and $x=5 / 12$ for the black planes, and positions $x=1 / 3$ and $x=1 / 2$ for the grey planes.

128 A slab of the structure corresponding to the coordination polyhedra of staurolite possesses only the 129 translational symmetry of staurolite; it has therefore to be described in the translationengleiche P1 130 subgroup of $C 2 / m$ (basis vectors of the twin lattice), in which every atom in the unit cell is 131 symmetrically independent and defines a crystallographic orbit. Restoration, if it occurs, concerns 132 atoms with the same structural role: we have therefore to consider the pseudo-eigensymmetry of 133 oxygen atoms, octahedral (X) cations, and tetrahedral ( $\mathrm{Y}$ and $\mathrm{Z}$ ) cations separately (we have 134 omitted the Fe1 and Fe2 sites because their very low occupancy makes their structural role 135 negligible). These are (quasi)-restored if the union of the corresponding crystallographic orbits 
contains a mirror or glide reflection about the (200) plane; in other words, if the pseudoeigensymmetry of the union of these orbits is of type $P m 11, P b 11, P c 11$ or $P n 11$. The analysis is presented in Tables S1-S48 (deposited material). Each table presents, for each of the three union of orbits (oxygen atoms, $\mathrm{X}$ cations, $\mathrm{Y} \& \mathrm{Z}$ cations) and for each position of the plane:

- the fractional coordinates of the atoms on the two sides of the plane nearest to that plane:

- the fractional coordinates of the same atoms on which the plane has acted as a mirror plane, $b$-glide plane, $c$-glide plane or $n$-glide plane, ordered in the sequence that minimizes the distance between corresponding atoms;

- the difference of fractional coordinates;

- the distance in $\AA$ between corresponding atoms:

- when the position of an atom obtained by mirror or glide-reflection is relatively close to more than one atom in their original position, the data of the former are shown in red: this means that the $1-1$ correspondence is broken and the atomic position obtained by mirror or glide reflection is midway between the atomic positions of two atoms in the slab of staurolite; this also implies that some of the atoms obtained by mirror or glide reflection do not have any of the atoms in the slab of staurolite as first neighbours; in this case, the atomic

154 The results, summarized Table 1, show that: coordination on the two sides of the plane is severely affected by the mirror or glide reflection.

- the oxygen orbits have a very high degree of pseudo-symmetry (very low distance d) for all the four cases $P m 11, P b 11, P c 11$ or $P n 11$ for black planes (which is not surprising because the corresponding atoms are almost on those planes); this is instead not the case for the grey planes;

- the X orbits have a very high degree of Pm11 pseudo-symmetry for the grey planes, but not 
for the black planes; this is also true for a subset of the orbits for Pn11 (75\%) and for an even smaller subset for $\mathrm{P} c 11$ (33\%), whereas no Pb11 pseudo-eigensymmetry exists for the black planes;

- a high degree of $\mathrm{Pb} 11$ pseudo-eigensymmetry exists for half of the $\mathrm{Y}$ and $\mathrm{Z}$ cations with respect to the black planes; no other pseudo-eigensymmetry for any of the other cases.

Restoration is considered to be achieved if the distance between corresponding atoms is shorter than atomic positions very close to each other (below $0.5 \AA$ ) and the other positions (above $0.9 \AA$ ). The best atomic restoration obtained in the Coray twin corresponds to the pseudo-eigensymmetry $\mathrm{Pb} 11$ on the black planes, i.e. planes at $(2 n+1) a / 12$, for which the whole set of oxygen atoms and half of the tetrahedral cations (of these, $1 / 3$ of $\mathrm{Y}$ and $2 / 3$ of $\mathrm{Z}$ ) are almost perfectly restored. This is however unlikely to be sufficient to give the twin a reasonable mechanical stability, considering that 1) in a

172 silicate, the bulk of the structure is represented by the tetrahedra centred on silicon, whereas in this 173 twin only half of the tetrahedra are restored across the twin plane (Fig. 5); 2) none of the octahedral 174 cations are restored. For the other eigensymmetries the situation is even worse, with either the 175 cations or the anions, but not both, restored. The structural continuity is therefore severely affected 176 and the coordination disrupted.

\section{Discussion}

178 The newly reported (200) twin in staurolite from Coray represents an exception with respect to the inverse trend usually observed between occurrence frequency on one hand and the degree of lattice restoration (as measured by the twin index and obliquity) on the other hand. Despite a degree of lattice restoration much higher (double) than that in the cross twins (Greek and Saint Andrews), it was never reported before.

183 The analysis of the structure at the twin plane, in terms of pseudo-eigensymmetry of the 
crystallographic orbits close to it, shows significant disruption of the coordination, which is instead largely preserved in the cross twins. This result naturally prompts the question as to the possible origin of this newly reported twin. It is well known that in a contact twin the composition surface is planar and, if twinning is by reflection, it is parallel to the twin plane (Sunagawa, 2005). On the contrary, in penetration twins the composition surface is irregular and the original composition plane, i.e. the one on which the change of orientation has originated (by the occurrence of a stacking fault, the deposition of an impurity or other perturbations) does not coincide with the twin plane; it plays an ephemeral role and disappears during the crystal growth (Kern, 1961). The Coray twin in staurolite is a penetration twin, which means that the composition surface most likely deviates from a plane; this may, to a certain degree, reduce the coordination disruption at the interface that would otherwise most likely prevent the occurrence of the twin. The (200) twin was never reported before. This may be an oversight, especially considering that morphological studies are less frequently performed today and morphological information is often unfortunately missing from structure refinements of twinned crystals. Otherwise, the extreme rarity of this twin, if confirmed, may suggest that the supposed compensatory effect of the irregular composition surface on the coordination disruption is probably limited.

Acknowledgements. We sincerely thank L.-D. Bayle, Editor of Le Règne Minéral, for his kindly agreement to reproduce his photographs of the Coray staurolite twin. Prof. A.M. Glazer (University of Oxford) has kindly proof-read the final version of the manuscript. Critical remarks by two anonymous reviewers are thankfully acknowledged.

\section{References}

Azevedo, S. \& Nespolo, M. (2017): Twinning in olivine group revisited. Eur. J. Mineral. 29, 213226.

Buerger, M.J. (1945): The genesis of twin crystals. Am. Mineral. 30, 469-482.

Chauris, L. (2014): Minéraux de Bretagne. Saint-Julien-du-Pinetè Editions du Piat, 336 p.

Dana, E.S. (1876). On new twins of Staurolite and Pyrrothite. Am. J. Sci. 11, 384-387.

Friedel, G. (1904): Étude sur les groupements cristallins. Extrait du Bullettin de la Société de 
l'Industrie minérale, Quatrième série, Tomes III e IV. Saint-Étienne: Société de l'imprimerie Thèolier J. Thomas et C., 485 pp.

Hawthorne, F. C., Ungaretti, L., Oberti, R., Caucia, F. \& Callegariwith, A. (1993): The crystal chemistry of staurolite; II, Order-disorder and the monoclinic $\rightarrow$ orthorhombic phase transition. Can. Mineral., 31, 551-582.

Hurst, V., Donnay, J. D. H. \& Donnay, G. (1956): Staurolite twinning. Mineral. Mag., 31, 145-163.

Kern, R. (1961): Sur la formation des macles de croissance. Bull. Soc. fr. Min. Crist. 84, 292-311.

Marzouki, M.-A., Souvignier, B. \& Nespolo, M. (2014a): Analysis of the structural continuity in twinned crystals in terms of pseudo-eigensymmetry of crystallographic orbits. IUCrJ, 1, 3948.

—, —, - (2014b): The staurolite enigma solved. Acta Crystallogr., A70, 348-353.

- , - - (2015): Twinning of aragonite - the crystallographic orbit and sectional layer group approach. Acta Crystallogr., A71, 195-202.

Moëlo, Y. (2018): Wanted! Une nouvelle macle de la staurotide à Coray (Finistère). Le Règne Minéral, 143, 31-34.

Momma, K. \& Izumi, F. (2011): VESTA 3 for three-dimensional visualization of crystal, volumetric and morphology data. J. Appl. Crystallogr., 44, 1272-1276.

Nespolo, M. (2015a): The ash heap of crystallography: restoring forgotten basic knowledge. $J$. Appl. Crystallogr., 48, 1290-1298.

Nespolo, M. (2015b): Tips and traps on crystal twinning: how to fully describe your twin. Cryst. Res. Techn. 50, 362-371.

- (2018): Twinning in chalcostibite revisited. Eur. J. Mineral., 30, 967-973.

Nespolo, M. \& Ferraris, G. (2004): The oriented attachment mechanism in the formation of twins a survey. Eur. J. Mineral., 16, 401-406.

-, - (2005): Hybrid twinning - A cooperative type of oriented crystal association. Z. Kristallogr. 220, 317-323.

—, - (2006): The derivation of twin laws in non-merohedric twins - Application to the analysis of hybrid twins. Acta Crystallogr. A62, 336-349.

_ , _ (2007): Overlooked problems in manifold twins: twin misfit in zero-obliquity TLQS twinning and twin index calculation. Acta Crystallogr. A63, 278-286.

Nespolo, M. \& Iordache, C. (2013): Twiny: from morphology to twin element and vice versa. $J$. Appl. Crystallogr., 46, 801-803.

Nespolo, M. \& Souvignier B (2015a): Application of the crystallographic orbit analysis to the study of twinned crystals. The example of marcasite. Cryst. Res. Techn, 50, 442-450.

-, - (2015b): Structural rationale for the occurrence of the elbow twins in cassiterite and rutile. $J$. Mineral. Petrol. Sci., 110, 157-165.

-, - (2017): Structural analysis of twins in feldspars. I. Carlsbad twinning. Eur. J. Mineral. 29, 939-947.

Smith, J.V. (1968): The crystal structure of staurolite. Am. Mineral., 53, 1139-1155.

Sunagawa, I. (2005): Crystals. Growth, Morphology, and Perfection. Cambridge: Cambridge University Press xii +295 pp. 
253 Figure 1. (a) Photo of the Coray twin sub-parallel to $b$ (reproduced from L.-D. Bayle, with his 254 permission). (b) Schematic drawing, with twin angle between A and B crystals. Arrow: view 255 direction of Fig. 2.

256 Figure 2. (a) Photo of the Coray twin sub-parallel to $a$ (reproduced from L.-D. Bayle, with his 257 permission). (b) Right. Schematic drawing.

258 Figure 3. (010) projection of the lattice of staurolite (black and yellow circles represent lattice 259 nodes with integer and semi-integer values of the $y$ coordinate). In black the unit cell of staurolite. 260 In red, the unit cell of the twin lattice. The indices " $\mathrm{I}$ " and "T" stand for individual and twin 261 respectively.

262 Figure 4. (010) projection of the structure of staurolite in the axial setting of the Coray twin, with 263 planes of the family (200) passing on or close to the oxygen atoms (black) or X cations (grey). This and the following figure drawn with VESTA (Momma and Izumi, 2011).

Figure 5. Overlap of the structure of staurolite about the (200) plane at $y=5 / 12$ (white atoms) and its mirror image obtained by $b$-glide reflection through this plane (black atoms). Only the quasirestored atoms are shown in the second case, i.e. oxygen atoms and half of the $\mathrm{Y}$ and $\mathrm{Z}$ sites.

Table 1. Percentage of restoration of crystallographic orbits around the (200) plane (setting of the twin) of Coray twin in staurolite for the four possible eigensymmetries. Details of the calculation are shown in Tables S1-S48 (deposited material). An atom is considered restored if the distance with respect to the corresponding position obtained by acting on it with the mirror or glide plane is lower that $0.5 \AA$, as explained in the text.

\begin{tabular}{|c|c|c|c|c|c|c|c|c|}
\hline & \multicolumn{3}{|c|}{ Planes at $(2 n+1) a / 12$ (black planes in Fig. 4) } & \multicolumn{4}{c|}{ Planes at $n a / 6$ (grey planes in Fig. 4) } \\
\hline & $P m 11$ & $P b 11$ & $P c 11$ & $P n 11$ & $P m 11$ & $P b 11$ & $P c 11$ & $P n 11$ \\
\hline $\mathrm{O}$ & 100 & 100 & 100 & 100 & 0 & 0 & 0 & 0 \\
\hline $\mathrm{X}$ & 0 & 0 & 0 & 0 & 100 & 0 & 33 & 75 \\
\hline $\mathrm{Y} \& \mathrm{Z}$ & 0 & 50 & 0 & 0 & 0 & 0 & 0 & 0 \\
\hline
\end{tabular}




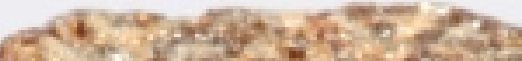

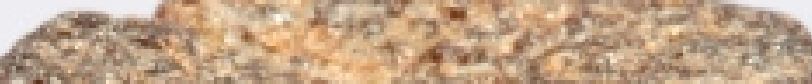

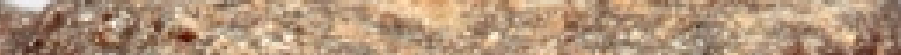

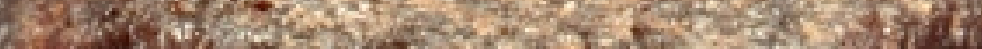

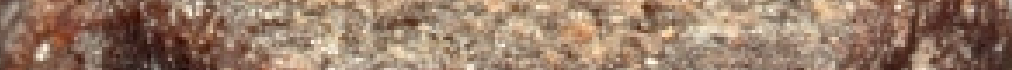

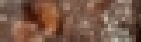

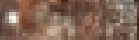

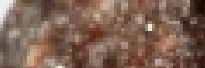

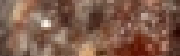

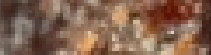
19:

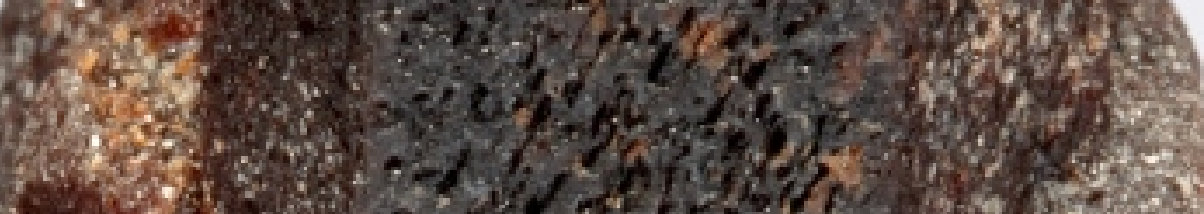

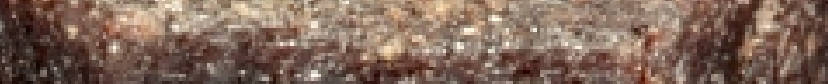
is:

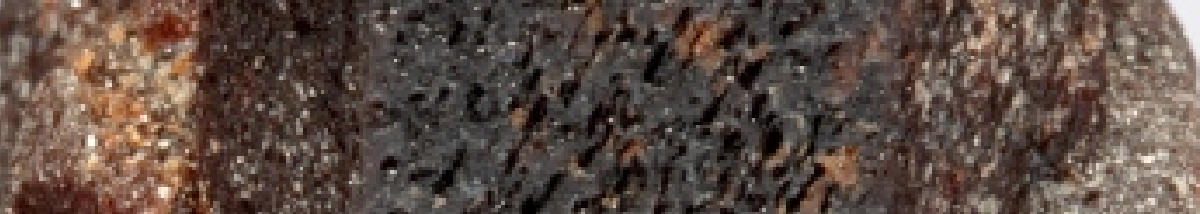

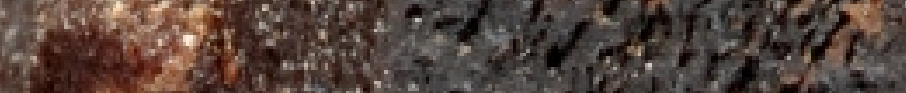
4

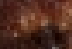

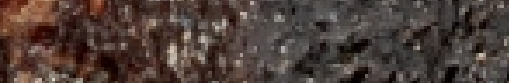

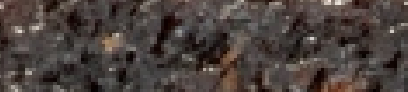

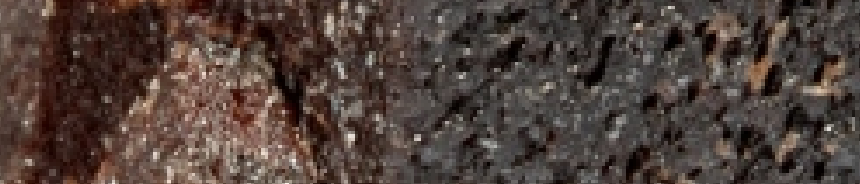

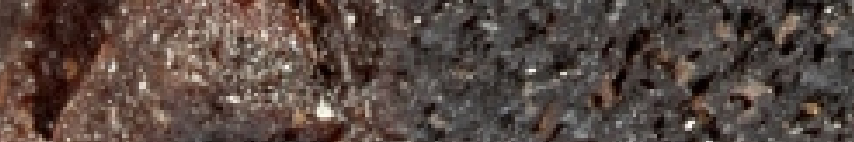

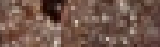

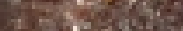

i. 3

i. s)

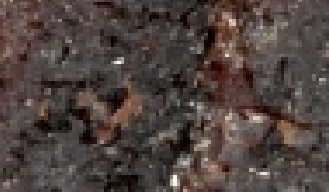

20 1

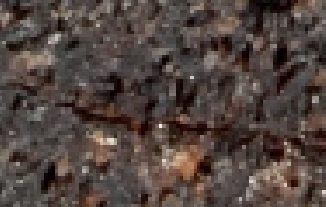

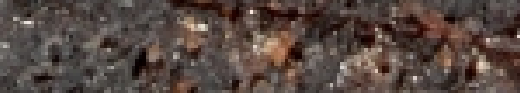

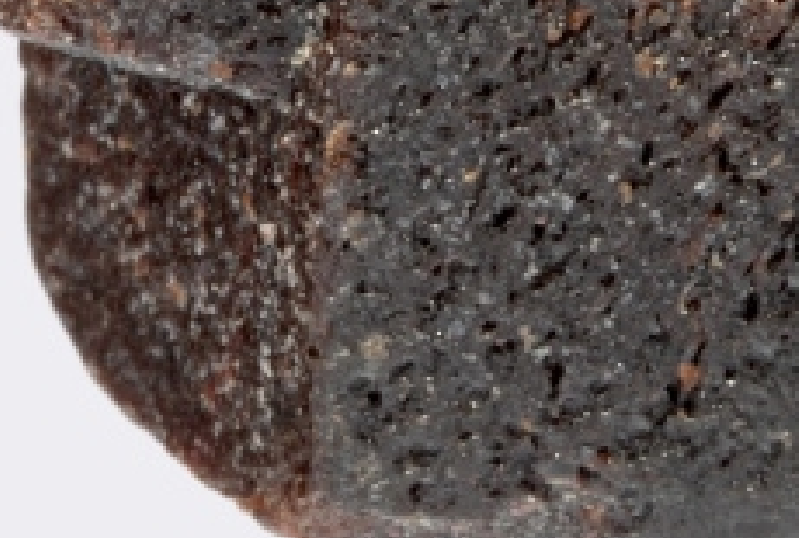




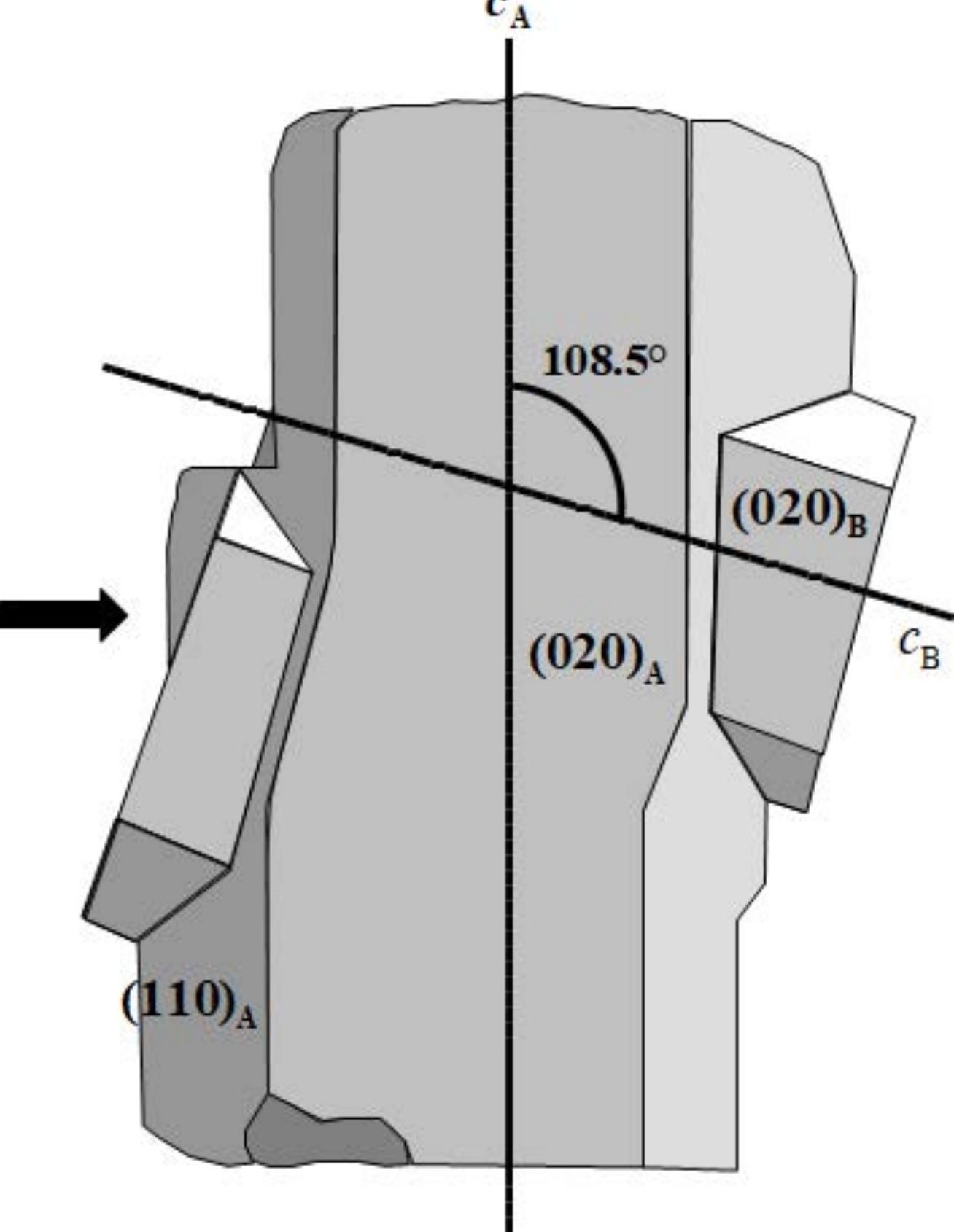




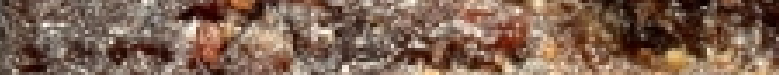

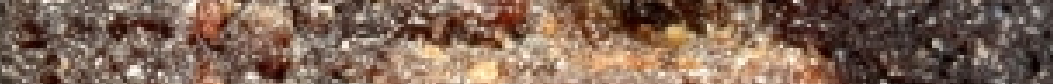

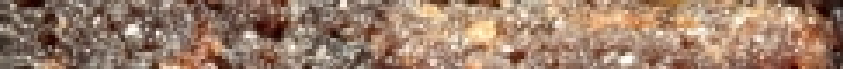

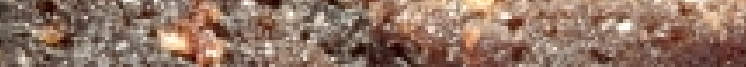

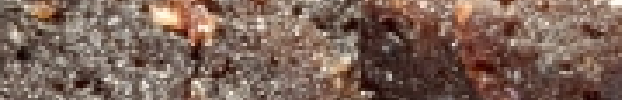

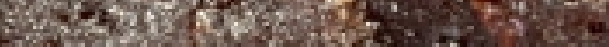
ares.

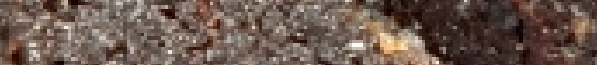

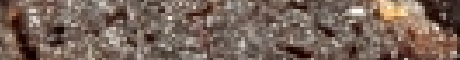

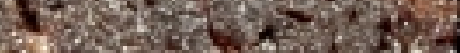

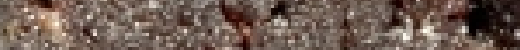

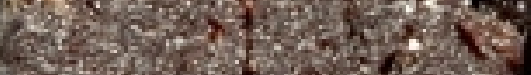
W.

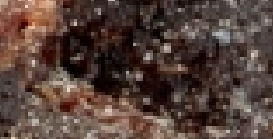

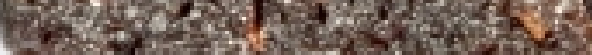





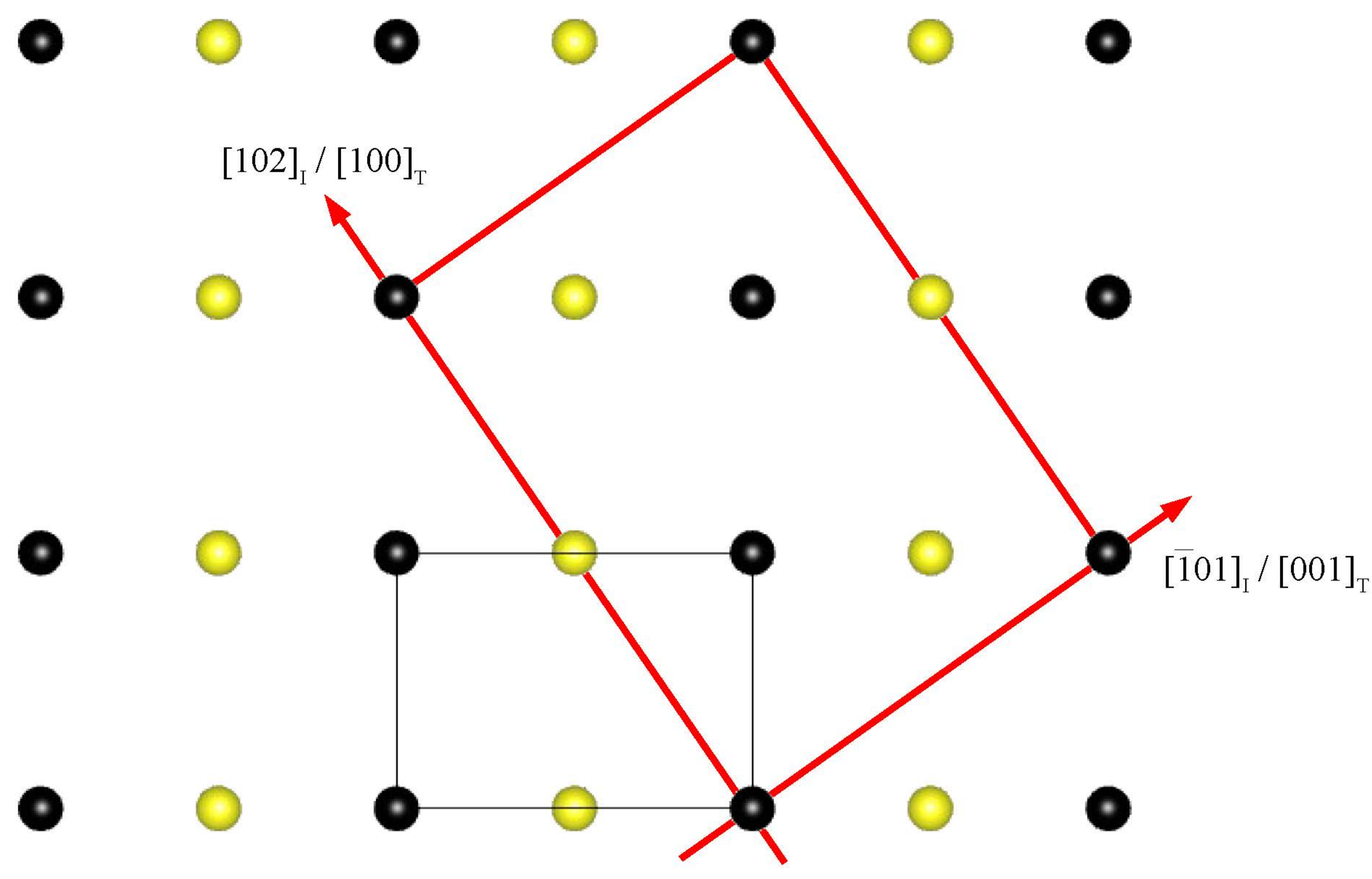




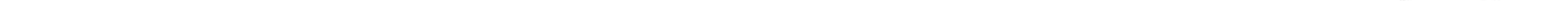


